\title{
La mayor eficiencia del Derecho espontáneo ofrece el camino para derrotar la informalidad: venciendo la interperie
}

Horacio Gago Prialé

\section{Resumen}

Este es un artículo sobre las posibilidades y dificultades para alcanzar sistemas jurídicos eficientes en países como el Perú de comienzos del siglo XXI: una nación típica del tercer mundo donde el setenta y dos por ciento de sus habitantes viven en ciudades (enorme transformación si se tiene en cuenta que en 1940 la población total era poco más de seis millones, y el sesenta y cinco por ciento habitaba el campo), cuatro de cada cinco activos son intercambiados fuera del sistema legal, tres de cada cuatro soles recaudados por la SUNAT provienen de tributos indirectos y el setenta por ciento de la fuerza laboral es informal. ${ }^{1}$ Sostenemos que en medio de tal precariedad institucional, los niveles de eficiencia jurídica sí existen, pero no se hallan en los sistemas legales oficiales sino que se encuentran en el derecho espontáneo de las actuales comunidades económicas emergentes, los hasta ayer asentamientos humanos y bolsones de economía informal, y un poco más atrás, invasiones de tierras, de Lima metropolitana y otras ciudades. Y que la institucionalidad por crear debe entroncarse en estos núcleos de eficiencia, para alcanzar una sociedad de equidad con reglas claras que impulsen las soluciones en vez de obstruirlas.

Entendemos por eficiencia de los sistemas jurídicos, el grado de ajuste entre las normas y sus resultados deseados, así como la cantidad, calidad y justicia en los intercambios de activos que esas normas facilitan en la práctica. Por normas entendemos, ya sea las leyes, las costumbres o las reglas producidas por la libertad civil de los agentes económicos; y cuando ha-

1 Censo de 1940, Hoja resumen de la Sunat, Cifras de OIT. 
blamos de «en la práctica» y «agentes económicos» nos estamos refiriendo preferentemente a los activos ${ }^{2}$ ubicados en aquellos fragmentos sociales aislados y desconectados donde se desarrollan mayoritariamente los intercambios, ahí en la denominada geografía de la informalidad.

Precisamos que se trata de una eficiencia limitada a los fragmentos o comunidades sociales (los asentamientos por ejemplo) que está empezando a expandirse impulsada por algunos mecanismos de representación de activos (títulos), en una tendencia orientada hacia la trascendencia de los valores de los activos hacia otros fragmentos, sin colisionar con los consensos particulares de cada uno, más bien armonizando y permitiendo que la punta de lanza sea la idea de que un activo busca a otro activo para combinarse.

De hecho, esa eficiencia ha sido estimulada por la creación de sistemas de conversión de activos mínimamente capaces de representar valores y extraer el capital potencial de esos activos como fuentes financieras, los mismos que han obtenido su eficiencia precisamente por haber sido instituidos utilizando los estándares y consensos de los mismos ex invasores, sus reglas y normas reales inventadas o generadas vía costumbre jurídica, y que legitimaron con el uso y destinaron a la finalidad de organizar sus asentamientos humanos. No otra cosa son los títulos de propiedad entregados por Cofopri, cuya misión, aunque pocos lo entiendan, no se limita a reconocer las tenencias de los ex informales, sino integrar activos a redes financieras nacionales y globales.

El formidable impacto de estos títulos, por ejemplo en el cono norte de Lima, es un indicador de lo que pueden hacer buenos sistemas de conversión de activos. No es difícil imaginar lo que esos sistemas podrían hacer cuando se consiga un sistema completo de derechos de propiedad adecuadamente fijado, cosa que no ocurre hasta la fecha y hasta podría estar peligrando. ${ }^{3} \mathrm{La}$ meta no es solo convertir activos prediales (y dentro

2 Los activos son de diverso tipo y todos ellos son susceptibles de valor y de intercambio: activos físicos (prediales, edificaciones, mobiliarios, recursos naturales), activos financieros (dinero o sistemas de representación de valor monetario), activos humanos (capital humano, conocimiento), activos sobre intangibles (propiedad intelectual: inventos, procedimientos, derechos de autor), y activos sociales (capital social, concepto nuevo que relata los factores que generan armonía social en los distintos grupos o comunidades humanas).

3 El peligro de que el proceso e formalización retroceda o se entrampe es real. Por ejemplo, de prosperar el pedido del Colegio de Notarios de Lima ante el Tribunal Constitucional para desconocer la validez de los formularios registrales ante el Registro Predial 
de los prediales, solamente el suelo) en terminales financieros, sino mucho más. Se trata de avanzar hacia mecanismos de conversión para el resto de tipologías de activos: no existen sistemas de representación de valores para edificaciones, bienes de capital, herramientas con las cuales los ex informales generan valor agregado a la economía, ni mucho menos activos intangibles: inventos, ideas, procesos, ahora en un archipiélago desconectado. ${ }^{4}$ Estos activos requieren sus propios «títulos» para alcanzar ese engranaje mayor de fijación de derechos de propiedad.

Nuestro análisis se basa en las investigaciones de campo realizadas por los estudiantes de Derecho del curso de Sociología del Derecho de la Pontificia Universidad Católica del Perú durante cuatro semestres académicos entre 2002 y 2003 y que se han sistematizado por los miembros del Grupo de Sistemas para la Inclusión Social, en su mayoría ex alumnos del curso. Estas investigaciones han dado respuesta concretamente a tres aspectos centrales:

\section{Derecho espontáneo}

¿Cuáles son las normas de Derecho espontáneo, es decir las normas extralegales, costumbres, usos generalizados, acuerdos legítimos, pactos básicos o reglas de juego que regulan la vida contractual, extracontractual, registral, formas de solución de conflictos y organizacional de los bolsones de actividad económica informal de Lima Metropolitana?

\section{Impacto de la titulación de COFOPRI}

¿Qué cambios se han dado en el desarrollo de la vida económica del asentamiento desde que se entregaron los títulos de propiedad de Cofopri? ¿Qué manifestaciones de nuevas relaciones jurídicas han aparecido al interior de los núcleos urbanos (asentamientos humanos), desde la culminación del proceso de formalización y titulación?

\footnotetext{
Urbano, se estaría dinamitando seriamente la posible generación de un sistema eficiente de derechos de propiedad.

4 Estudios recientes del Banco Mundial indican que la seguridad de derechos sobre intangibles se encuentra en la base de la solidez del crecimiento económico y desarrollo institucional de una economía. Ver Hisamitsu Arai (actual jefe de la Estrategia Japonesa sobre Propiedad Intelectual) y Stijn Claesness: «Financial Development, property rights and Growthw (World Bank Policy Research Working Paper 2924, November, 2002) .
} 


\section{Precarización de títulos}

¿Cual es la situación de los derechos de propiedad de las zonas urbanas en las que históricamente ha existido una definición antigua y tradicional de solares y derechos de propiedad? ¿Es demostrable la hipótesis de que la mayor parte de esos predios se encuentra en manos de poseedores precarios, tenedores y arrendatarios sin contratos, debido a que los derechos de propiedad se han debilitado, fragmentado o desaparecido?

\section{Qué ocurrió en las colinas de arena}

Sobre lo que ha ocurrido en las ex colinas de arena, ${ }^{5}$ hoy convertidas en distritos populosos de la Lima informal ( $\mathrm{y}$ muchas ciudades del tercer mundo) se han tejido tres argumentos distintos: dos extremistas (de signo contrario, uno conservador y el otro utópico) y uno tercero ubicado entre ambos extremos, que podría denominarse realista.

De un lado, los conservadores niegan legitimidad a la ola de invasiones de la segunda mitad del siglo XX (indiscutiblemente ilegal), porque en un estado de Derecho, en el cual existen instituciones y procedimientos para acceder a los beneficios de la ley, toda usurpación es un acto violento que debe ser penado, y las invasiones son despojos y hechos atentatorios de las esenciales normas de convivencia. Agregan que la obtención de la propiedad tiene sus modos previstos en la legislación civil y que entre ellos no cabe el acto de invadir un terreno baldío, se halle abandonado u ocupado. En esta misma esquina se lamenta que el Estado se haya visto en la necesidad "social" de reconocer la odiosa presencia de los informales (lo que hiciera al crear Cofopri), y se acepta este retroceso como un mal necesario, cuando no un error histórico que lo único que puede traer es más informalidad. Lo que queda, dicen, es formalizar esta realidad desde el Estado para esterilizar ese mundo caótico y predatorio con la vacuna de la ley y los principios que la inspiran. Entonces, cuando se disputa un mejor derecho posesorio en Villa el Salvador, por ejemplo, se cita a Ihering y Savigny ${ }^{6}$ (lo hemos visto recientemente en un examen de grado para op-

5 Tomo prestada la frase del doctor Fernando de Trazegnies Granda.

6 Resolución del Tribunal Administrativo de Formalización No 1999-002-COFOPRI/ TAF del 20 de enero de 1999. Vocales del tribunal de COFOPRI: César Guzmán-Barrón Sobrevilla, César Albrecht Mas y Sergio Tafur Sánchez. 
tar el título de abogado) y con ello se lleva «Derecho», "principios jurídicos», "doctrina» a la nueva periferia urbana a fin de tender un puente hacia ella y civilizarla jurídicamente. Esta es una posición de profunda raigambre positivista. Desde esta orilla, que lamentablemente alberga a la mayoría de abogados peruanos, se entiende muy poco sobre la potencialidad de los sistemas jurídicos de alcanzar niveles de eficiencia, precisamente porque ésta se extrae de dentro de la vida social, desde los hechos jurídicos.

En el otro extremo se encuentran los utópicos, quienes ven la migración sobre las ciudades como un acto de reivindicación milenaria del hombre andino (o de cualquier hombre del tercer mundo que decide tomar revancha contra viejos procesos coloniales y cercar las ciudades en donde se concentran los núcleos del capitalismo). De este modo la ciudad será el escenario donde repetir y revivir su esencia comunal y demostrar que las sociedades colectivistas están vivas y crecen. Prueba de ello son, dicen, los comedores populares, las ollas comunes, las rondas urbanas, la enormidad y complejidad de las asociaciones populares, los comités de autodefensa, etc. piezas todas de un solo escenario: la gran comunidad solidaria que se nutre de órganos comunales, en donde la propiedad privada se halla neutralizada. A este mundo hay que reconocerlo y estimularlo en su esencia comunal. Esta es una suerte de posición neo indigenista, y como todo indigenismo, una construcción idealista y ficticia, desde la cual tampoco se puede discernir sobre la utilidad de los sistemas jurídicos para combinar adecuadamente activos físicos, humanos o financieros, precisamente porque se trata de una posición que niega el esencial hecho de que las comunidades sociales aspiran, como ocurre en la realidad, a esa combinación eficiente.

Entre ambos extremos se perfila la posición realista, en la cual nos encontramos, y que sostiene que los sistemas jurídicos operan de modo dialéctico, que son la consecuencia de un permanente proceso de interacción entre la realidad viva de los agentes individuales o sociales de los distintos grupos, y las normas que ellos mismos generan o adoptan para asegurar sus intercambios, primero al interior del grupo o comunidad, y después entre el grupo y otras comunidades del exterior, incluido el gobierno local o el Estado, con sus leyes. Hecho / norma es la dicotomía dialéctica de cualquier sistema eficiente, al que toda sociedad humana tiende, tanto aquella de reciente existencia en las colinas de arena de Lima, como la que se yergue a orillas del río Támesis desde centurias atrás o la que apareció sobre el Potomac. Para los realistas el Derecho no es una imposición 
civilizatoria que llueve como maná una vez que el Estado, con la mano extendida y llena de sabiduría, reconoce y permite la formalización, adiestrando a las comunidades sociales en los principios romanistas, contractualistas, estructuralistas o legalistas de que son duchos los juristas del positivismo.

Pero tampoco creen los realistas que los modos de organización colectiva cancelaron la tendencia individualista, inevitable y poderosa, abierta por los grupos humanos volcados a las ciudades en busca de la modernización imposible en el mundo rural. Mas bien, subrayan la decadencia de ese cuasi extinto escenario comunal y se fijan en el vuelco migratorio que protagonizaron los grupos humanos de casi toda la faz del planeta durante la segunda mitad del siglo XX sobre sus ciudades, atraídos por el neón de las calles y los mercados extensos de las urbes, repletos de promesas de prosperidad individual.

Es un hecho de la realidad que la revolución informal que irrumpió tras el vuelco migratorio campo/ciudad fue un acto de profunda transformación social y económica que protagonizaron los hijos de los hijos de los comuneros indígenas de las alturas de Junín y Pasco, entre otros. Y que se trató de una revolución radicalmente distinta a la ansiada revolución colectivista añorada por los marxistas criollos; fue más bien una revolución por las libertades económicas y el funcionamiento de mercados extensos, que en arenales y terrenos baldíos creó conglomerados económicos sensacionales, entre los que se pueden mencionar algunos de la Lima de los conos: Los Olivos, Comas, Ventanilla, Carabaillo, Villa El Salvador, Ate, Huaycán, Villa María del Triunfo, etc. Pero, además, los informales, con su revolución, no solamente provocaron el derrumbamiento del paradigma marxista, una de las plagas sociales del siglo XX, sino que chocaron frontalmente y con éxito, contra la estructura mercantilista del Estado peruano, una segunda plaga histórica. Es decir, han sido los informales los que conmovieron de raíz dos de las tres columnas de la idea del Perú como problema. La tercera plaga, el militarismo, subsiste.

Es desde esta visión realista y entroncada en el hecho jurídico donde hemos encontrado mayores posibilidades de descubrir el hilo de la madeja de la eficiencia de los sistemas jurídicos en el Perú. ${ }^{7}$

7 Sobre la importancia y perspectivas de la sociedad espontánea como portadora de un sistema jurídico legítimo, ver Horacio Gago Prialé, Sociedad Espontánea y Derecho, Civitas, Madrid, 2000. 


\section{La partera de la historia}

Estas líneas de argumentación se ubican en un contexto que impone tres precisiones puntuales:

Una. Las invasiones de tierras que dieron luz a los asentamientos humanos fueron agresivas, repentinas y aleves, sin duda; es un hecho que la sociedad espontánea peruana nació con dolor. Pero su violencia no cancela el argumento realista. Lo que hace es confirmar que las instituciones legales oficiales que regían "en la teoría" sobre esos espacios vacíos antes de las invasiones, eran débiles, inexistentes o, cuando menos, discutibles. Si lo contrario, es decir, si había un Derecho consolidado que fue violentado, cabe cuestionar: ¿Cómo entonces aparecieron a los pocos años órdenes espontáneos, fuera de toda legalidad, que asignaron derechos de propiedad, resolvieron disputas de linderos, generaron reglas contractuales al interior de sus espacios que al final el Estado tuvo que reconocer y hacer suyas cuando echó a andar los procesos de formalización de la propiedad?

La violencia de las invasiones, más bien, da pie para recordar que la propiedad en toda sociedad en formación suele alcanzar su primer peldaño (la tenencia) de modo violento. No hay que esforzarse mucho para percatarse del origen de muchas haciendas, casonas, fundos y latifundios del Perú en el pasado, que con los años dibujaron la geografía catastral oficial: basta recordar a qué manos y cómo fueron a parar las tierras de las comunidades indígenas en el siglo XIX así como las que resultaron de la desamortización de tierras de la Iglesia. Se trató de violentos despojos en contra de las comunidades indígenas, a las que se les arrinconó en las zonas altas e improductivas de las punas, a golpe de vara $\mathrm{o}$, como poco, de sentencias judiciales compradas; cuando no de una apropiación subrepticia de las ex propiedades eclesiásticas; o también de despojos solapados a través del uso de la ley para arrancar predios y tierras a favor de grupos privilegiados. Pero esto no solo en el Perú. La historia de tomas violentas de tierras y espacios "vacíos» es general en occidente, siendo uno de sus paradigmas la conquista del oeste norteamericano que hizo tabla rasa de órdenes sociales preexistentes, pero que con el tiempo dio lugar al sistema jurídico más eficiente de la historia: los Estados Unidos.

Dos. Este debate no refleja solamente una visión política o doctrinaria sobre la complejidad de los procesos de inclusión económica y social de los informales peruanos, sino también y preferentemente, una puesta en vigor de los alcances que el Derecho tiene con relación a los problemas de 
desarrollo de la sociedad y economía peruanas. En este sentido, se entiende al Derecho como un sistema coherente de soluciones para la convivencia social y el hallazgo de la justicia concreta (ya provenga de la ley, la costumbre o la libertad contractual), y se concibe al desarrollo como la meta donde los instrumentos jurídicos impulsan un uso óptimo de los recursos escasos. El Derecho y Desarrollo se pregunta si las normas legales aportan mayor velocidad y seguridad o, mas bien, entrampan y envilecen la combinación y movilización de los activos existentes en el mercado, el cual, ya sabemos, está mayoritariamente ubicado en la sociedad espontánea informal. El debate tiene una naturaleza jurídica medular y la disciplina llamada Derecho y Desarrollo es su mejor escenario.

Y tres. Queremos decir que, aun cuando la disciplina de Derecho y Desarrollo, tan en boga en universidades norteamericanas y británicas, no tenga un despliegue mayor en América Latina, al Perú le cabe un papel emblemático en materia de experiencias de inclusión social. Es un país que, junto con Tailandia, en el círculo de expertos rememora la idea de un proceso de formalización de propiedad predial relativamente exitoso (pese a Cofopri, diría Hernando de Soto). Recuérdese que fue el Perú el primer escenario sobre el cual se desarrolló una seria investigación de los alcances y verdadera naturaleza de la explosión informal. Hernando de Soto y el Instituto Libertad y Democracia desde 1987 con la aparición de El Otro Sendero, le voltearon la carga al análisis sobre el vuelco migratorio campo / ciudad. De una visión, más bien utópica, en la línea de El Desborde Popular de José Matos Mar, el tema fue encarado en términos de la capacidad de los informales de generar desarrollo económico. Hoy en día, la existencia de emporios comerciales aparecidos precisamente gracias a los programas de formalización, como el del cono norte de Lima, son la respuesta que la realidad ofrece a la percepción acertada de los ochentas que entendió el vuelco migratorio como una revolución por la propiedad y la generación de mercados, a diferencia de la visión utópica marxista.

\section{Derecho sin ley}

En el grupo de Sistemas para la Inclusión Social (SIS) y en el curso de Sociología del Derecho de la Pontificia Universidad Católica del Perú, trabajamos en un análisis de la funcionalidad y operatividad del hecho jurídico al interior de los fragmentos sociales urbanos de Lima, utilizando 
casos reales. Nuestro análisis microjurídico se concentra en las estructuras obligacionales en los ámbitos de la llamada informalidad, ahí donde la ley escrita oficial no marca las pautas ni dirige las decisiones jurídicas de los grupos humanos o personas individuales. De este modo, hemos observado la racionalidad que subyace en la asignación de cargas y beneficios, esto es, de justicia jurídica concreta, en el mundo de los conglomerados informales. Lo que nos convoca es la existencia y funcionamiento del Derecho sin la ley, esto es, la generación de orden y eficiencia en la movilización de activos en base a reglas de Derecho espontáneo. Sin códigos ni leyes, hemos recorrido, ordenada y sistemáticamente, por las experiencias jurídicas, impactos y carencias de los instrumentos normativos espontáneos con los que la gente informal desarrolla su vida económica y social.

No nos sentimos aislados en este esfuerzo. De hecho, el enorme impacto mundial que han ganado las tesis institucionalistas (de Soto, North, Becker, Stiglitz, Giddens, Held) se debe en gran parte a la reflexión común en torno a la necesidad de encontrar los incentivos para obtener instituciones eficaces en los pozos o reservas de realidad, esto es en la vida social, en el plano de lo existente, en los hechos, tal como hacemos en SIS con los hechos jurídicos espontáneos. Se ha pasado de un positivismo cientifista sustentado en un conglomerado de abstracciones racionalistas a un realismo que intenta encontrar el orden de las cosas en los datos de la realidad. Kant ya no reina más.

En el ámbito de lo estrictamente espontáneo, debemos mencionar las investigaciones de Norman Barry, ${ }^{8}$ profesor de The Buckinghan University del Reino Unido, y por supuesto las de Robert C. Ellickson, ${ }^{9}$ profesor de The University of Yale, quien en los años noventa desarrolló un estudio sobre los modos de solución de conflictos entre los rancheros de Shasta County, en California, y concluyó que la mayoría de gente encuentra muy caros e irracionales los costos que supone entrar en conocimiento de las leyes y procedimientos judiciales, y que optan por lo más sencillo: recurrir a las normas del sentido común que ellos mismos generan. Es decir, algo que nosotros en el Perú vemos todos los días realizar de modo mayoritario en los conos y asentamientos humanos.

8 Norman Barry, «La tradición del orden espontáneo», en: Revista Acta Académica, Número 27, Universidad Autónoma de Centro América, noviembre de 1997.

9 Robert Ellickson, Order Without Law: How Neighbors Settle Disputes, Harvard University Press, Cambridge, Mass, 1991. 
A partir de estas observaciones podemos colegir y confirmas ideas centrales, muchas de ellas simples pero quizá, precisamente por ello, de una profundidad muy grande.

\section{Sociedad e individuo}

La idea de sociedad e individuo es esencial en este recuento. Michel Villey, ${ }^{10}$ uno de los mayores filósofos del Derecho del siglo pasado, subraya que el Derecho se halla en el mundo de la justicia particular, que es objetiva y en un ámbito exterior al sujeto, ahí en el orden social; a diferencia de la Moral, que más bien relata el mundo de la justicia general, el universo de las virtudes del sujeto, interior y personalísima. Ello significa que un sistema jurídico lo que atiende no es hacer más bondadosas, altruistas o solidarias a las personas (función de la familia, la educación, la religión), sino únicamente permitir una equitativa y adecuada (justa) distribución de cargas y beneficios concretos, en el mundo de lo externo al sujeto, en el ámbito de lo social. El Derecho atiende al orden social y sus mecanismos buscan la distribución equitativa de proporciones.

Pero lo que emparienta a la Moral (el género) con el Derecho (la especie), es que, así como un acto moral puede no ser jurídico (obligatorio, exigible), un acto jurídico sí tiene que ajustarse a una moral básica: la de la equidad. Esta palabra, equidad, es ese link entre el universo subjetivo de la Moral y el objetivo del Derecho. Es en el nivel de la epiqueya de los griegos, donde se construye la pauta que el Derecho debe observar para hallar el dato de justicia particular que le interesa, pauta que indica que una solución de Derecho va a estar siempre basada en la equidad, es decir en el respeto básico de opciones libres y de contenido racional objetivo.

La justicia particular se halla inmanente en las cosas ("la cosa" debe entenderse como el objeto sobre el cual dos o más partes pueden generar obligaciones jurídicas), de modo que un contrato es jurídico porque tiene una justicia intrínseca que consiste en distribuir proporciones, de acuerdo a ciertos indicadores para medir la equidad (méritos, capacidades, valor de activos) y no solo porque satisfaga los intereses de las partes. De hecho, un contrato entre amantes para matar al marido de ella no es jurídico,

10 Michel Villey, Compendio de Filosofía del Derecho, Universidad de Navarra, Pamplona, 1979. 
sería un pacto criminal, y en consecuencia antijurídico. Los intereses de las partes son un elemento, pero no son «el elemento» que genera la juridicidad. El Derecho es el orden de lo justo particular, y lo justo particular en el Derecho es encontrar el punto medio en la distribución de beneficios o cargas entre dos o más partes. Nada más, pero tampoco nada menos.

Los terrenos de la filosofía del Derecho, esto es, del estudio de los fines y fundamentos del Derecho son de una fecundidad muy grande para descubrir la racionalidad de los sistemas jurídicos; pero lamentablemente, aunque parezca paradójico, son muy poco frecuentados por los abogados. Incluso, el mismo Análisis Económico del Derecho desatiende o posterga la discusión sobre la justicia de las reglas de juego y la moral que encierran, aun cuando existen soberbias excepciones, como los ensayos del juez norteamericano Richard A. Posner, quien funda la moral del AED en el principio de la maximización de la riqueza como criterio ético rector de los sistemas jurídicos en general. Para Posner la riqueza es algo que a nivel de los jueces debe ser promovido: «la reducción de la desigualdad no contribuye a mejorar significativamente la estabilidad de una sociedad, pero el aumento de su nivel de riqueza sí produce tal efecton, ${ }^{11}$ dice Posner.

Esencialmente lo que nos interesa ahora es que el Derecho es el to dikaion de Aristóteles (recuperado por Villey), que quiere decir el objeto que resulta de una distribución justa de lo que a cada quien corresponde. Esta idea guarda relación con la de los jurisconsultos romanos (no nos referimos a los compiladores bizantinos, sino a los juristas del tiempo republicano romano, cuando el derecho se hacía de la mano de los hechos y bajo el impulso de los pretores) y su idea de la res iusta, el quid iustum est, que al igual que el to dikaion aristotélico, no significan nada más ni nada menos que una idea de distribución de cosas y proporciones partidas y repartidas según criterios del justo medio.

Eso es Derecho, dar a cada uno lo suyo, un resultado que atiende a fines, objetos finales, un hallazgo de una adecuada distribución o repartición de proporciones.

Llamar derecho a la ley o a la costumbre no es del todo incorrecto, pero sí impreciso. La ley lo que permite es encontrar el Derecho, el punto medio en cada caso concreto, se trata de un medio, una herramienta. No confundamos el fin, el resultado de justicia particular, el Derecho, con los

11 Richard A. Posner, Frontiers of Legal Theory, Harvard University Press, 2001. 
medios, es decir los instrumentos de que se vale el jurista para determinar el justo medio en el caso. Los instrumentos son eso: herramientas, medios, ayudas, pautas para que el juez, árbitro, o quien haga sus veces en las distintas instancias de organización social, alcancen el dato de justicia particular; pero no el fin en sí mismo. Es decir las leyes, las costumbres, los principios generales, la doctrina, la naturaleza de las cosas, no son otra cosa que factores instrumentales para un fin, encontrar el to dikaion en cada caso particular.

Confundir medios con fines puede ser devastador, como lo demostró la debacle del positivismo legalista que hasta ahora padecemos y que se inició tras la segunda guerra mundial. Convertir la Ley en todo el Derecho, haciendo abstracción de la justicia, que es en pocas palabras lo que se hizo con el ideal kelseniano del Derecho puro, significó el trastrocamiento del sistema legal y su colapso como fuente de soluciones reales. Esto nos es muy familiar en el Perú en la medida que cuando miramos a los cuatro costados nos topamos con imágenes en las que la Ley es vulnerada de uno u otro modo. Si nos limitáramos a percibir el orden jurídico en ella no cabría otra conclusión que calificar ese escenario como el reino de la anomia. Y si concluyéramos tal cosa, por fuerza, nos perderíamos el impacto, realidad y efectos concretos que la revolución urbana informal de la segunda mitad del siglo XX ha tenido en la economía, la sociedad y la marcha hacia los mercados extensos y organizados.

Los instrumentos de Derecho están pensados para generar orden y permitir una convivencia provechosa para todos. Pero hay algo más y muy importante. En realidad lo que hacen esos instrumentos es lograr que los hombres combinen sus activos. El Derecho es el «lenguaje que hablan los activos", el código de visibilidad que les hace entrar en combinación para beneficio de sus titulares. Lo que hacen los hombres es inventar mecanismos para crear nuevos y mejores titulares de activos, y luego reglas de bajo costo para poder intercambiarlos con eficiencia, usando recursos escasos en la obtención de seguridad y velocidad. Eso es lo ideal. Pero se requiere de un sistema de propiedad claro y bien fijado. ${ }^{12}$

12 El capítulo 3 de El Misterio del Capital de Hernando de Soto es insustituible consulta en este tema. De Soto explica con genio los modos cómo operan los sistemas de conversión de activos y mecanismos de representación de valores. 


\section{Sociedad, orden y pluralidad}

Entonces, si de lo que se trata es de repartir equitativamente cosas, beneficios o cargas entre personas, está claro, como lo sostiene Aristóteles, que se necesita de una sociedad mínimamente ordenada, funcional y en la que se distinga con nitidez a los agentes sociales, las personas o las partes interactuantes. Un ámbito en el que los agentes no son susceptibles de repartirse nada, o donde no haya agentes claros, no podrí facilitar la existencia del Derecho. Ya que nos encontramos en el mundo de las distribuciones, entonces por lo menos tenemos que saber quienes pueden ser pasibles de recibir proporciones. Esto es esencial ${ }^{13}$.

De ahí la importancia de distinguir la esfera subjetiva o moral, en la que no hay nada que repartir, de la objetiva o social, la jurídica.

Para que haya Derecho se requiere de sociedad clara y agentes nítidos a fin de que las reglas aplicables a los intercambios sean fluidas. Cuando Aristóteles se detiene en este punto no debe creerse, sin embargo, que su búsqueda conduce a sociedades ideales, homologadas y de sujetos idénticos. No. Toda sociedad es plural y diversa, toda nación está formada por grupos con intereses, estímulos, formación, valores y creencias múltiples. Incluso, los países más homogéneos admiten en su seno altas dosis de pluralidad por la sencilla razón de que los seres humanos somos diferentes unos de otros. Somos entidades individuales irrepetibles, marcadas por una singularidad esencial, seres que compartimos ciertas características comunes que son las que nos hacen precisamente sujetos sociales. Pero nuestra singularidad está fuera de duda, lo que significa que podemos, de hecho, desarrollar sistemas de convivencia en los que nuestra individualidad se vea satisfecha y nuestra sociabilidad, esto es, nuestra necesidad del otro, también sea viable. Todas las sociedades humanas son plurales y están compuestas por personas diferentes, con sus propias particularidades y señas de identidad inexportables.

Lo anterior no siempre es correctamente entendido. Lo que ocurre en el tercer mundo, el Perú por ejemplo, a diferencia del primer mundo, es que no hemos desarrollado reglas comunes que saquen adelante esquemas

13 De ahí que Villey dude de la existencia de verdadero Derecho al interior de la familia. Para Villey la familia, comunidad de amor, no es el mejor ámbito para asignar a cada quien lo que le corresponde. Un hijo aplicado y otro rebelde van a recibir el mismo plato de comida. 
eficientes de convivencia y de adecuada combinación de nuestras diferencias. En el Perú lo que creemos es que el problema de los sistemas jurídicos ineficientes consiste en la carencia de una sociedad homogénea, paritaria, intercambiable, como si los seres humanos fuéramos bienes fungibles. Erróneamente cerramos los ojos al problema de la ineficiencia del Derecho en el Perú causado dentro del sistema jurídico.

Por supuesto que las causas de la ineficiencia jurídica están dentro del Derecho, en los procesos normativos legales, en cómo se generan las leyes y cómo se gerencia este proceso. Lo que no podemos hacer es sustraer al Derecho de la responsabilidad de generar mecanismos útiles y seguros, con el argumento de que los peruanos somos muy distintos unos de otros y que por eso no nos entendemos obligacionalmente. En absoluto. Todas las sociedades son plurales, diversas, complejas, y lo que hacen los seres humanos es justamente organizar reglas para sacar adelante una convivencia provechosa, que incluso obtiene sus frutos de los aportes procedentes de los grupos diversos.

El Perú es una sociedad de sociedades sumamente fragmentada, pero no lo es más ni menos que Estados Unidos o Brasil. Sin embargo, lo que nos hace débiles es que a esa fragmentación se le añade la desconexión, la carencia de puentes legales entre los fragmentos. Lo que nos debilita es la ausencia de instituciones que generen reglas que todos utilicen en tanto se trata de reglas válidas, útiles, que resuelven problemas concretos y que permiten a los activos nuevas y más sofisticadas combinaciones.

El individuo es un centro de deseos, anhelos. Lo que lo hace jurídico es el hecho de convivir en sociedad. Existe fuera de la sociedad pero necesita de ella para ser plenamente hombre. Vallet de Goytisolo, ex Presidente de la Real Academia de Jurisprudencia de España y connotado jurista civil dice: «Aunque la sociabilidad es congénita al hombre, este no deja, por ello, de ser esencialmente hombre aún fuera de la sociedad o no ejerciendo funciones sociales. La persona es sustancial y ontológicamente incomunicable, metafísicamente solitaria. Su comunicabilidad es operacional, fruto de la relación interpersonal, de la que resulta la vida social. Pero si bien el hombre no es fruto de las relaciones sociales, tampoco se realiza como hombre sin la aportación que recibe de tales relaciones». ${ }^{14}$

La «insociable sociabilidad del hombre" hace al ser humano generar reglas para coexistir y sacar adelante lo que él es: un manojo de anhelos,

14 Juan Vallet de Goytisolo, Metodología Jurídica, Civitas, Madrid, 1988, p. 25. 
ideales, apetitos. El hombre no está impulsado por la solidaridad en sus actos, sino por sus anhelos de prosperidad y bienestar. La solidaridad, el amor, son ingredientes de los círculos internos de la sociedad, que dibujan los puntos de referencia, estructuran esas redes internas de la personalidad humana necesarias para su afirmación individual, pero de ninguna manera son los ingredientes esenciales de su participación en la sociedad. Lo hace mas bien para buscar mas y nuevos espacios de prosperidad a través de intercambio de intereses, beneficios. Entonces y solo por ello está dispuesto a ceder y transigir. A respetar reglas. Un hombre está en situación de ceder en sus pretensiones máximas a cambio de llegar a acuerdos, acuerdos que le permitan alcanzar sus fines. Esa es la ecuación básica de equidad: A cumple sus pactos con B, y B con A por interés de que A y B se respeten mutuamente sus espacios.

Esta idea está vinculada con otra que indica que las personas nos relacionamos primero con otras personas de nuestro entorno social y que para ello preferimos las reglas de nuestra localidad antes que las generales de la nación. Ellickson lo percibe así entre los granjeros de Shasta County y nosotros entre los comerciantes de El Progreso en Carabayllo, por poner un ejemplo. Las personas tendemos a prácticas usuales, en círculos de confianza cercanos.

Pero ello no quiere decir que una vez que la ecuación de equidad ya opera, las personas y los grupos sociales no queramos expandir nuestras posibilidades de prosperidad. Sujetos sociales y expansivos al fin, ese manojo de apetitos y anhelos que somos, se ve influenciado por las múltiples maneras en que recibimos la información procedente de otros fragmentos, y tendemos a abundar en las combinaciones de la misma ecuación en nuevas zonas y en modos mas sofisticados. Entonces, si alguna querencia tenemos es a buscar satisfacer nuestros deseos y necesidades de prosperidad. En ese esfuerzo nos nutrimos de la experiencia ganada en practicar intercambios con reglas de confianza y apostamos a que fuera del fragmento también seamos capaces de encontrar reglas y pautas para intercambiar activos.

\section{La matriz de la eficiencia juridica}

La necesidad de respeto de las reglas está sustentada en el uso que se da a ellas. El uso, la práctica, la legitimidad de esas normas que dan solucio- 
nes al interior de los fragmentos son la autentica matriz de la eficiencia de los sistemas jurídicos. Tan simple como ello. El uso legitima a la norma (sin perder de vista la justicia particular). En este escenario los instrumentos de coerción tienen una utilidad secundaria.

Joaquín Costa, el jurista alto aragonés que explicó como ninguno el funcionamiento de la costumbre jurídica, sostenía que «la ley supletoria es sencillamente una costumbre de Derecho y aun cuando se halle traducida en una ley o introducida en un código, no deja de ser costumbre, o más claro, no tiene nunca otra fuerza que la que le da el hecho de ser practicada por esa generalidad, por esa mayoría». ${ }^{15}$ Al legislador no le está permitido convertir en ley supletoria cualquier estipulación, trasplantándola o trasmitiendo su particular personalidad, sino que las presunciones deben ser racionales, "conformes a la realidad de las cosas», agregaba Costa.

La sociedad espontánea del Perú tiene una dinámica jurídica sofisticada y compleja, siempre espontánea, con la ventaja de que sus reglas, por ser legítimas y sustentadas en el uso, pueden alcanzar los resultados que se proponen.

Entonces, si la matriz de legitimidad es la práctica, se debe colegir que las leyes, costumbres, contratos, instituciones sin uso, no son parte de ningún sistema jurídico, mas bien tropiezos administrativos de los que se halla plagados las legislaciones ineficientes.

Ahora, aún cuando los pozos de legitimidad y eficiencia se encuentran en el mundo del Derecho vivo, a nivel del uso y las prácticas que solucionan problemas efectivos, también es cierto que esas reglas se dan, primero a partir de situaciones álgidas. Lo que estamos diciendo es que las reglas se tejen siempre de abajo arriba, y que parten desde las áreas mas esenciales hacia las más sofisticadas. Y esa "zona cero» en la que se concentra la atención primaria de los grupos sociales y de las personas individuales, es, qué duda cabe, el tema de la propiedad. Punto de partida, espacio de anclaje, centro de ubicación de la individualidad, la propiedad es el eje articulador de todo el sistema jurídico. Lo vemos en la historia de las invasiones de las colinas de arena que protagonizaron los informales peruanos.

15 Joaquín Costa, Derecho Consuetudinario y Economía Popular de España, Joaquín Costa, Santiago Méndez, Miguel de Unamuno y otros, tomo I, Barcelona, 1902, Manuel Soler Editor, $2^{\text {a }}$ edición aumentada, Biblioteca de autores españoles y extranjeros, p. 381 y ss. 
Cuando los provincianos llegaron a Lima no lo hicieron con la consciente y racional vocación para la creación de mercados. Ellos no pensaron que se iban a las arenas a construir emporios económicos, «megaplazas» o ciudades del futuro. Lo primero que sintieron fue una profunda y primaria necesidad de ubicarse físicamente en un pedazo de suelo. Luego de hacerlo y generar reglas de juego esenciales, surgirían poco a poco las condiciones para que ese orden evolucione hasta niveles económicos significativos. Una vez que supieron echar esas raíces básicas pudo operar recién la mano invisible.

De ahí la importancia de entender la eficiencia de un sistema jurídico desde su raíz: la propiedad. Los derechos de propiedad bien definidos son la base sobre la que asentar todo el sistema. La ecuación en este caso es simple: A que es propietario de una casa respetará la propiedad de B, impulsado por el esencial hecho de que no desea que $B$ obstruya su derecho sobre su casa. Solo un propietario individual, cuyo derecho es inobjetable, puede entender que exista propiedad en manos de otros, y que el beneficio de todos pasa por la defensa y el respeto de esa propiedad. Solo un propietario inobjetable puede entender que haya espacios públicos que son comunes, de propiedad de todos: parques, calles, veredas, mares, pues son los espacios que le dan sentido y ubicación a su propiedad individual. Solo un propietario indubitable va a entender la necesidad de respeto del espacio ajeno y del espacio público, precisamente porque necesita que respeten el suyo.

\section{La confianza}

Pero ese respeto solo será posible si existe confianza. Las combinaciones entre activos van a ser jurídicas cuando las reglas tengan orientaciones hacia la justicia particular, y para ello los hombres necesitan confianza (por eso también es que esos intercambios tienen que ser justos, equitativos, satisfacer los términos de intercambio). Los seres humanos movilizamos nuestros activos en el ámbito social en zonas de confianza. Buscamos confianza para desarrollar intercambios. La confianza es esencial, y tenemos que aportarla.

Los países desarrollados, entendiendo como desarrollados a aquellos que cuentan con sistemas jurídicos eficientes, aportan la confianza a través de la ley. Las instituciones legales del sistema son las portadoras de esa 
atmósfera en la que los intercambios se desarrollan. En el tercer mundo, la confianza no es brindada por el Estado a través de la ley. Esa es la diferencia. La ley no delimita los espacios para la confianza; únicamente encarna la voluntad del Estado, esa entidad débil, lerda, de presunta omnipresencia y escasa realidad, que habla a través de la ley para exponer su voluntad, pero que no transporta la voluntad ni racionalidad de los grupos sociales. En el Perú, por ejemplo, la ley no aporta la confianza, solo da un indicador al mercado de lo que el Estado quiere, y el mercado lo que hace es utilizar esa información como un punto de referencia en el momento de establecer los costos de los intercambios. En el Perú, la confianza se construye y reconstruye todos los días dentro de los fragmentos sociales, utilizando el derecho espontáneo de las comunidades locales, su propio Derecho, en base a reglas vivas.

Aquí es útil comprobar nuevamente que en este análisis no nos encontramos solos ni que nuestra sociedad espontánea es el engendro antropológico de caos y anomia como lo suelen calificar observadores desavisados. David Friedman, profesor de Santa Clara University, en California, y uno de los más originales juristas del AED recoge el concepto de Schelling points ${ }^{16}$ en los siguientes términos: que esta noción permite acercarse al funcionamiento de los sistemas de generación de consensos al interior de un grupo o comunidad, e incluso al interior de una relación jurídica dada, y así entender la racionalidad de los intereses que se hayan detrás de los acuerdos que satisfacen mutuamente a las partes. Se trata de una importante base conceptual para confirmar que las reglas espontáneas funcionan con mas precisión en tanto satisfacen necesidades y agradan intereses.

Debemos decir que todas las sociedades humanas, tanto de los países desarrollados como del tercer mundo, funcionan en base a grupos reducidos, esferas y fragmentos sociales, yuxtapuestos e integrados unos dentro de otros, dentro de los cuales existen reglas de Derecho aplicables a la solución de los problemas de intercambio de activos (reglas para definir derechos de propiedad, regular contratos, resolver disputas, definir responsabilidad por daño civil o acceder a información sobre activos y contratos). Pero entre unas sociedades y otras hay una diferencia básica. Los países desarrollados han sistematizado y estandarizado sus consensos es-

16 David D. Friedman, "A Positive account of property rights", en: Social Philosophy and Policy, vol. 11, number 2, Cambridge University Press, 1994. 
pontáneos y luego han conectado a través de una red de reglas legitimadas por el uso los distintos fragmentos que conforman su sociedad. Se trata de sociedades fragmentadas pero conectadas, física y legalmente. Se puede decir, entonces, que en este mundo el Derecho casi equivale a la ley.

En el tercer mundo la cosa es diferente. Los fragmentos sociales se encuentran en una especie de archipiélago sin conexión entre sí, y sus reglas de Derecho tienen una validez normalmente limitada al fragmento. El Estado no ha sistematizado ni estandarizado esas reglas espontáneas, como sí ha ocurrido en el mundo desarrollado. En el tercer mundo, el Derecho está por un lado y la ley por el otro. En breve, en el primer mundo pocas normas resuelven muchos casos concretos, mientras que en el tercer mundo muchas reglas resuelven pocas situaciones reales.

En el Perú, esos pozos de legitimidad normativa que resuelven situaciones reales dentro de las comunidades fragmentadas no han sido ampliados a otras zonas, o por lo menos no en su mayoría. Existe una enormidad de reglas particulares y una gran cantidad de modos de solución de conflictos. Las concentraciones informales aplican su Derecho fragmentario dentro de su esfera, y ha sido con este Derecho fragmentario que los grupos informales han logrado acumular la cantidad de activos que Hernando de Soto calcula en más de 90 mil millones de US dólares. Pero no debe creerse que esta acumulación se ha generado con un único tipo de reglas; de hecho han participado cientos, miles de ellas, correspondientes a tantos fragmentos sociales.

Pero ello no quiere decir que esa ampliación no tenga que darse. El impacto de la titulación de Cofopri al interior de los asentamientos humanos, demuestra que la lógica de la expansión tiene clara vigencia cuando se dan ciertas condiciones (ver análisis de casos prácticos en este mismo artículo). Más bien la pregunta debe ser: ¿Por qué Cofopri sí funcionó y no así los anteriores procesos de reforma y formalización? Con lo cual se llega a la única respuesta posible: porque gracias al predicamento e investigaciones del ILD, lo que el Estado peruano hizo en ese caso, fue recoger el Derecho espontáneo, sistematizarlo y colocarlo en una ley. Se nutrió de su eficiencia y ahí los resultados. No existe otra respuesta.

En resumen, los hechos reales que impulsan los acuerdos particulares, que a su vez dan cuerpo a las reglas generales que los hacen cumplibles y posibles, crean una red de instituciones espontáneas que les dan sistemática y seguridad. Estas instituciones son invento humano y provienen de las practicas de los hombres, sustentadas en sus necesidades particulares, 
impulsadas por su socialibilidad y su individualidad. Su eficiencia está sustentada en el uso. Y es precisamente el uso lo que las legitima y da funcionalidad, por encima de los esquemas coercitivos.

No se olvide que los sistemas jurídicos son un invento humano, y que el Derecho es un universo de instrumentos que se sustenta en gran parte en mecanismos de representación que permiten intercambios de activos de modo masivo, lo que es posible a través de esquemas que representen esos activos. Para llegar a ese nivel de eficiencia es necesario confiar en la naturaleza humana y conocer su tendencia hacia la prosperidad, comunicación y la creación de vínculos nuevos y reglas para intercambiar sus activos. Nada mejor que descansar en el uso efectivo que esos instrumentos normativos tienen en sus fragmentos.

Si es que esos instrumentos existen es porque son usados y si son usados es porque son legítimos y efectivos, y si es así, merecen convertirse en pautas generales para guiar mayores y más complejas decisiones, fuera de las comunidades locales reducidas.

Una vez que se entienda esto podrá asimilarse mucho mejor la tesis de Hernando de Soto sobre los sistemas de conversión de activos, que no es otra cosa que la generación de capital o nuevas realidades económicas a partir de su anclaje en activos físicos. Y captar así que la galaxia donde cada activo pueda hacer efectivo su potencial financiero puede ser aspiración natural de todo ser humano, sin que ello signifique que la casa que tanto costó obtener, deje de ser un lugar para vivir y guarecerse de la intemperie.

\section{La eficiencia de lo espontáneo en directo}

En los trabajos realizados por el Grupo de Sistemas para la Inclusión Social desde el año 2002, hemos verificado que la población ha creado su propio Derecho, ante la ineludible necesidad de efectuar transacciones comerciales, obtener financiamiento y capital de sus predios, cuya premisa fundamental es la confianza. Confianza que hace insertar a un individuo dentro de un bolsón económico y le favorece en el hecho de estar incluido dentro de un sistema jurídico fáctico. Ahí donde el Estado ha creado mecanismos de inclusión es donde han surgido nuevas zonas de comercio y negocios ganados a la oscuridad de lo informal y se ha activado un sinnúmero de factores económicos dormidos para el mercado pro- 
ductivo, generando tras de sí toda una serie de acontecimientos que dan solidez a zonas económicas pujantes y creativas, como es le caso del Cono Norte de Lima, ejemplo de lo que puede hacer una creatividad jurídica viva.

Hemos visto en acción al Derecho espontáneo y observado que se trata de una respuesta ágil, inmediata y creativa a la ineficiencia del Derecho legal. Cada manifestación tiene una racionalidad como base, pues el hecho de que la respuesta sea espontánea no la convierte en irracional, hay una lógica y una coherencia tras cada paso jurídico de este Derecho, que busca dar patrimonialidad a aquellos activos excluidos por los excesivos formalismos del sistema legal estatal. Los informales han logrado crear bolsones económicos con reglas claras y soluciones eficaces a sus necesidades e intereses, dando vida a su capital, que de no ser así enmohecería a la espera de alguna providencia política o legal.

Esta espontaneidad, versátil y eficiente, sin embargo no oculta sus problemas: no logra desarrollar a plenitud todo el potencial capital que tienen estos activos, pues el Derecho espontáneo, por mas buena voluntad que ponga no será un mecanismo sólido de representación de activos, logro que requiere de un sistema jurídico legal y legitimo de representación de activos. El problema es que el Derecho espontáneo no es legal y el Derecho formal no es legítimo.

\section{Para corroborar lo dicho tenemos diversos ejemplos:}

1. El caso del Asentamiento Humano «Hijos de Ventanilla», ubicado en Cerro Negro de Ventanilla-Callao, con 5300 habitantes aproximadamente, cuenta con organizaciones de base ágiles concentradas en sus problemas relevantes. En este sector urbano hubo fallidos procesos anteriores de titulación: Ministerio de Vivienda (1988), Concejo Provincial del Callao (1992-1993), antes del llevado a cabo por el Estado a través de Cofopri. Solo este pudo vitalizar las transacciones comerciales, ha permitido el acceso al crédito, la constitución de garantías y por ende ha reconocido para la legalidad un innumerable mundo de relaciones jurídicas que se perdían antes inexorablemente para el contexto y tráfico comercial. Gracias a la activación de aquellos predios se han producido enormes cantidades de contratos de compra-venta y contratos de arrendamiento. Los inmuebles han sido objeto de varias figuras jurídicas, revalorizando sus 
precios a la medida que el mercado se agiliza y se acomoda a la vitalidad jurídica.

Al entrar al sistema dichos activos generaron una cadena de acontecimientos. A la activación, siguieron los créditos, al haber financiamiento surgieron los negocios familiares, llegó capital externo en forma de cadenas comerciales dedicadas a distintos rubros, tales como los de comida rápida, educación, electrodomésticos, diversión, etc. Esto creo una zona comercial a lo largo de las avenidas principales tal como ejemplifica la Avenida Andrés Avelino Cáceres, que ahora luce plagada de una vida comercial tenaz. Tras esto llegaron los servicios, es decir se ha creado ya una zona dinámica creciente y creadora de capital, fomentando los valores del mercado y además paralelamente incentivando la educación. El mercado educativo se materializa en la creación de colegios particulares de todo nivel y academias preuniversitarias, prueba de que una vez producido el proceso de inclusión, la capitalización de los activos de las poblaciones ajenas al sistema legal pone en juego un capital humano con potencial productivo inmedible.

2. Otro caso dinámico lo encontró el Grupo en el mercado de pescados de Ventanilla, con una Administración que poseía dos caras jurídicas, una mirando al exterior frente al sistema legal, lenta y proclive a la corrupción; y otra, extremadamente ágil y creativa hacia el interior del mercado, con innumerables relaciones jurídicas y con tratos dinámicos y diferenciados, encarnada en diversas agremiaciones de estibadores, minoristas y fileteros, dándole una complejidad y a la vez una riqueza jurídica al movimiento diario del mercado.

Los hechos jurídicos aparecen con una versatilidad y una variedad inusitada. Aquí el factor trascendental es la confianza y la dinámica, se hacen contratos de transferencia de bienes (pescado), con garantías factibles de ser ejecutadas en horas ante el incumplimiento. Hay formas de financiamiento con tasas moratorias por horas, la dinámica y complejidad es aplastante, pensar en figuras legales aquí es utópico y reaccionario. La espontaneidad bulle, nadie tiene tiempo de meditar en el hecho de que están creando Derecho, la eficacia es el paradigma. La patrimonialidad aquí encuentra las figuras jurídicas necesarias para dar vitalidad a los diversos intereses particulares en juego. La administración tiene contratos de arrendamiento con minoristas y fileteros con rentas distintas cada día; la falta de pago extingue sin trámite el contrato, la dinámica es la mayor coerción para que cada parte cumpla con sus prestaciones. Los conflictos 
son resueltos por la administración o la agremiación, según sea la jurisdicción competente ante el caso concreto; y dada la dinámica, todos acatan las decisiones pues más se gana volviendo a la dinámica que acudiendo al conflicto abierto.

3. Otro caso, esta vez con bienes muebles, lo tenemos en el mercado de venta y fabricación de muebles de Villa el Salvador. Aquí encontramos una concentración económica con una dinámica ágil y un Derecho espontáneo eficaz y coherente. La palabra clave en este bolsón es la confianza; la mayoría de las transacciones de bienes se da entre agentes del bolsón que se conocen y tienen lazos consolidados a través del tiempo. Proveedores, fabricantes e intermediarios ya tiene un juego jurídico conocido y respetado, aquel que obvie las reglas será relegado y perderá la posibilidad de pertenecer al bolsón, siendo después de aquello una persona sin crédito y sin posibilidad alguno de comerciar. Aquí se producen contratos verbales de transferencia de bienes, créditos entre conocidos con mecanismos de garantías y ejecución de estas respetados por todos. Un ejemplo es la transacción de bienes futuros con garantía personal, notable solución si se tiene en cuenta que el código civil no permite las garantías sobre obligaciones futuras. La espontaneidad jurídica resuelve eficazmente las necesidades fácticas patrimoniales, ante la anorexia práctica de la juricidad legal. Hay también un sistema dirigencial eficiente que funciona a través de agremiaciones de productores que interceden por todos ante las autoridades y se encargan de ser un órgano jurisdiccional respetado de solución de conflictos.

4. Como otra prueba de lo afirmado tenemos el caso de la precarización de los títulos en el centro de Lima, específicamente en las zonas de ParuroHuallaga y Wilson-Colmena. Aquí se encontró que la gran mayoría de los poseedores de los predios y negocios eran poseedores con títulos cuestionables, desconociendo muchos quien era el real dueño de los predios que ocupaban. Aproximadamente el $90 \%$ de los poseedores de los inmuebles, lo hacen con títulos distintos a la de la propiedad. De estos poseedores, un $85 \%$ son arrendatarios o subarrendatarios siendo el resto de ellos poseedores precarios evidentes. Los contratos de arrendamiento formales son complejos, pero dada la necesidad del comercio, hay innumerables contratos de arrendamiento y subarrendamiento verbales. La mayoría de los negocios carecen de algún requisito formal para un operar legalmente. 


\section{$X$. Inclusión y equidad social}

Puede entenderse que buscar la eficiencia de un sistema jurídico tiene un alto componente de para qué y para quien ese sistema es eficiente. La respuesta es que se trata de hacer un sistema inclusivo, que integre a quienes están fuera y que en el tercer mundo quienes se encuentran fuera no son las minorías, sino los grupos mayoritarios. Dijimos al comienzo que la OIT reconocía que el setenta por ciento de la fuerza laboral en Perú se encontraba desarrollando sus actividades en el sector informal. Y es cierto. Nuestra investigación combinada tiene como objetivo generar marcos, programas, sistemas y guías de acción basados en los principios de justicia e equidad y desarrollar opciones para lograr objetivos sociales y crear conocimiento para servir a la comunidad.

En los países pobres, el termino desigualdad es un asunto primordialmente asociado con exclusión social o mas específicamente, con la exclusión de la actividad económica, la exclusión de la participación política y la exclusión de la integración social. Estas son características crónicas y muy antiguas de la desigualdad en los países pobres.

En años recientes, el interés por el tema de la desigualdad ha experimentado un resurgimiento en la literatura académica, así como en la agenda internacional. Este resurgimiento es la culminación de una variedad de tendencias analíticas, empíricas y políticas. Las reglas que determinan los modelos de inversión, comercio, finanzas y el orden monetario siguen generalmente hechas en los países ricos. Sin embargo, este estilo de arriba hacia abajo de hacer e imponer las reglas, está siendo altamente cuestionado en los países del sur e inclusive dentro de los países del norte. Hay dos razones fundamentales para esto. La primera es la ausencia de la convergencia entre los países pobres y los países ricos, entre los que no tienen y los que tienen. La segunda es el proceso de integración global, la cual no necesariamente es la responsable de que la diferencia entre los ricos y los pobres, entre los que tienen y los que no tienen, sea cada vez mas grande, sino que la integración global nos muestra casi instantáneamente las profundas desigualdades que existen dentro de los países y entre los países.

Sin duda, una de las características mas resaltantes de la desigualdad es la diferencia en el ingreso entre los individuos dentro de un país y entre los países pobres y ricos a nivel mundial. Estas desigualdades se dan porque existen diferentes habilidades para obtener ingresos, por ejemplo teniendo un sistema económico mas orientado a los servicios que a la ma- 
nufactura o agricultura. Un segundo nivel de desigualdad se halla dentro de los mismos países pobres entre una influyente minoría y una vasta mayoría. Esta dicotomía, como lo observan Seligson y Passe-Smith ${ }^{17}$ (1998) también puede ser vista en las zonas urbanas como en las villas rurales. En conclusión, los pobres de los países pobres vienen experimentando una situación de «doble riesgo», en la cual no solo la desigualdad va en aumento con relación a los individuos de los países ricos, sino que también se encuentran rezagados con relación a sus compatriotas ricos.

En el campo de las relaciones internacionales, la desigualdad es debatida. Pero no asoma en ese debate la consideración del grado de influencia que puede tener un régimen doméstico o nacional para aliviar las desigualdades. ${ }^{18}$ La diferencia en el ingreso entre los países ricos y pobres ha crecido dramáticamente desde el fin de la segunda guerra mundial aun cuando en teoría el nuevo orden internacional que emergía de ella debería estar basado en la igualdad entre los países y en que todo país debería ser tratado en igualdad de condiciones en la sociedad internacional. Citando a Woods (1999, p. 12) fue esta especie de "fundación igualitaria» la que apoyó la descolonización y la auto-determinación de los pueblos, así como la fundación de las instituciones internacionales como las Naciones Unidas, organizadas en base a una nación un voto.

Prontamente, los países en vías de desarrollo, más pobres que nunca, se desilusionaron con la idea formal de igualdad en la política mundial. La descolonización y el acceso a las instituciones internacionales no resultó en un sustantivo incremento de igualdad. Por esta razón, desde 1960 en adelante, los países en vías de desarrollo presentaron continuamente el tema de la desigualdad ante la comunidad global. En términos mas exactos, ellos proponían un mayor grado de «igualdad distributiva».

Desde los ochentas, la desigualdad fue borrada de la agenda nacional e internacional y fue reemplazada por ideas de auto-ayuda, es decir los individuos y naciones pobres deberían tomar responsabilidad sobre sus propias preferencias y actos. El subdesarrollo era ahora explicado en términos del fracaso de las políticas que cada país en vías de desarrollo había implementado. Estos fracasos se reflejaron en el manejo de la crisis de la

17 Seligson, M.A. y Passe Smith, J.T. Development and Underdevelopment: The Political Economy of Global Inequality, Boulder, Lynne Reiner, 1998.

18 Ngaire Woods y Andrew Hurrell, Inequality, Globalization and World Politics, Oxford University Press, 1999. 
deuda. El pedido de justicia seria confrontado con el llamado a abrir los mercados donde fuese posible.

En la retórica política, por un lado, el argumento fue enmarcado para asegurar que el mercado disciplinaría a los regímenes corruptos. Por otro lado, una acción concertada para restringir y regular el accionar de las organizaciones internacionales fue llevada acabo. Los costos del cambio de ideología fueron considerables para los países en vías de desarrollo: el flujo de ayuda internacional hacia los países pobres fue declinando, la asistencia y la cooperación se volvieron condicionales al cumplimiento de la dirección de la política, digitadas en Washington. Las teorías sobre el desarrollo fueron revisadas. En general, y por el resto de los noventas, la brújula indicaba la reducción del rol del estado, es decir eliminar el rol redistribuidor del Estado dentro de una economía.

En el Perú, la exclusión social va mas allá que el concepto antes mencionado. El Perú tiene un sistema mercantilista basado en la exclusión social. En este sentido, la pobreza puede ser entendida como la expresión mas común y visible de la exclusión social. Pero ojo, los pobres no están excluidos necesariamente de todo lo demás. Como trabajadores informales, ellos están involucrados en el proceso de producción, están reconocidos como ciudadanos y se identifican así mismos con aquellos valores culturales propios de una nación. 